\title{
Desenvolvimento sustentável no Órgão de Solução de Controvérsias da Organização Mundial do Comércio: demolindo mitos e barreiras
}

\author{
Ligia Maura Costa \\ Fundação Getulio Vargas / Escola de Administração de Empresas de São Paulo / \\ Departamento de Fundamentos Sociais e Jurídicos \\ São Paulo / SP - Brasil
}

\begin{abstract}
A noção de desenvolvimento sustentável inclui justiça social, distribuição da renda, pleno emprego, segurança e saúde no ambiente de trabalho, proteção ambiental e bem-estar socioeconômico. Este artigo traz uma análise comparativa das disputas trazidas à OMC, desde a entrada em vigor da instituição em 1o de janeiro de 1995 até 1o de janeiro de 2014, relacionadas com elementos do desenvolvimento sustentável. O objetivo é examinar a extensão e a natureza do conceito de desenvolvimento sustentável no sistema de solução de controvérsias da OMC através dos exames da "jurisprudência" da OMC. É fato que a OMC enfrentará, num futuro próximo, desafios ligados à noção de desenvolvimento sustentável. A habilidade da OMC para conciliar a liberalização comercial multilateral com o desenvolvimento sustentável em seu sistema de solução de controvérsias é uma preocupação central à legitimidade dessa instituição.
\end{abstract}

Palavras-chave: OMC; sustentabilidade; desenvolvimento sustentável; órgão de solução de controvérsias.

Desarrollo sostenible en el Órgano de Solución de Diferencias de la Organización Mundial del Comercio: rompiendo mitos y barreras

La noción de desarrollo sostenible incluye la justicia social, la distribución del ingreso, el pleno empleo, la salud y la seguridad en el trabajo, protección del medio ambiente y el bienestar socioeconómico. Este artículo presenta un análisis comparativo de las diferencias planteadas en la OMC desde la entrada en vigor de la institución en 1 enero 1995 hasta 1 enero 2014 y las cuestiones relacionadas con el desarrollo sostenible presente en muchas de estas disputas. El artículo busca examinar el alcance y la naturaleza del concepto de desarrollo sostenible en el sistema de solución de diferencias de la OMC por el examen de la jurisprudencia de la OMC. No se puede negar que muchos retos que el sistema de

DOI: http://dx.doi.org/10.1590/0034-7612139082

Artigo recebido em 11 ago. 2014 e aceito em 10 jun. 2015. 
la OMC tendrá que enfrentar en el futuro próximo están vinculados a la noción de desarrollo sostenible. La posibilidad de conciliar la liberalización del comercio multilateral de la OMC con el desarrollo sostenible es una preocupación central para la legitimidad de esta institución.

Palabras clave: OMC; sostenibilidad; desarrollo sostenible; órgano de solución de diferencias.

Sustainable development issues in the Dispute Settlement Body of the World Trade Organization: breaking down myths and barriers

The concept of sustainable development includes social justice, equal income distribution, full employment, safe and healthy working environments, environmental protection and socio-economic welfare. This paper intends to provide a comparative analysis of sustainable development issues inside the WTO dispute system based on the analysis of the cases presented to WTO since January $1^{\text {st }} 1995$ until January $1^{\text {st }} 2014$. This paper proposes to analyse the extent and nature of the incorporation of sustainable development issues into WTO dispute settlement through the analysis of the WTO "case law". No one can deny that the WTO will face in the near future challenges related to sustainable development issues. The WTO's ability to reconcile multilateral trade liberalization with sustainable development in its system of dispute is a central concern to the institution's legitimacy.

KEYWORDs: WTO; sustainability; sustainable development; dispute settlement body.

\section{Introdução}

No final do século XX foi criada a Organização Mundial do Comércio (OMC), resultado das negociações comerciais multilaterais da Rodada Uruguai. O valor fundamental da OMC está na liberalização do comércio de bens, serviços e dos aspectos relacionados à propriedade intelectual (Flory, 1999:29; Jackson, 2000:34; Hudec, 2002:82; Amaral Júnior, 2002; Thorstensen, 2003:78). A noção de desenvolvimento sustentável não está presente nos temas delineados pelos Acordos abrangidos da OMC. Todavia, não se pode negar que o desenvolvimento sustentável está atrelado à liberalização comercial. É fato que a liberalização comercial e o desenvolvimento sustentável estão inter-relacionados. Não se pode, hoje, avançar de um lado sem concomitantemente proteger o outro. Tanto é assim que os Acordos da OMC trazem um total de 155 disposições dirigidas aos países em desenvolvimento e aos seus problemas crônicos de desenvolvimento. Durante muito tempo, porém, a conexão entre assuntos, aparentemente tão distintos, sequer foi mencionada.

Desenvolvimento sustentável, no âmbito da OMC, se faz presente no Preâmbulo do seu Acordo Constitutivo, que reconhece, expressamente, que os Países-Membros objetivam

a elevação dos níveis de vida, o pleno emprego e um volume considerável e em constante elevação de receitas reais e demanda efetiva, o aumento da produção e do comércio de bens e de serviços, permitindo ao mesmo tempo a utilização ótima dos recursos mundiais em conformidade com o objetivo de um desenvolvimento sustentável. 
No mesmo sentido, a Declaração de Doha reafirma o compromisso dos países-membros da OMC com o desenvolvimento sustentável (Cesar e Sato, 2012:174) e acrescenta que

(...) o intuito de sustentar e salvaguardar um sistema multilateral aberto e não discriminatório, e agir em vista à proteção do meio ambiente e à promoção do desenvolvimento sustentável pode e deve ser apoiado mutuamente.

(...)

Reconhecemos que, de acordo com as regras da OMC, nenhum país deve ser impedido de tomar medidas para proteger à vida humana, animal ou vegetal ou à saúde, ou ao meio ambiente, nos níveis que considerar apropriados, desde que estes não sejam utilizados de modo a constituir uma forma de discriminação arbitrária e injustificada entre os países, onde as mesmas condições devem prevalecer ou, uma restrição disfarçada ao comércio internacional e que, de outra forma, esteja de acordo com as disposições dos Acordos da OMC.

A liberalização do comércio internacional de bens, serviços e propriedade intelectual somente pode funcionar de modo eficaz diante de um mecanismo de resolução de disputas eficiente (Petersmann, 2005). Isto porque, como bem lembra Luiz Olavo Baptista, "a segurança jurídica é um dado fundamental nas relações entre seres humanos” (Baptista, 2007:19), e tal segurança se perfaz por meio de um sistema eficiente de solução de conflitos. O Órgão de Solução de Controvérsias (OSC), criado para exercer esse papel, tem respondido de modo adequado às expectativas. A jurisdição obrigatória de todos os países-membros outorgada ao OSC, aliada à possibilidade de sanção, foi um avanço considerável na história do direito internacional (Baptista, 2007:17). A OMC tem "dentes" — para usar a expressão que fez fortuna na doutrina especializada — , mas ela só pode "morder" em presença de violação aos seus Acordos, violações essas refletidas em procedimentos discriminatórios que levem a obstaculizar o comércio mundial (Faini e Grilli, 1997:102, Hudec, 2002:84; Costa, 2005:167). Estender essa regra de ouro para abranger a noção de desenvolvimento sustentável, que está presente apenas de modo oblíquo nos Acordos da OMC, pode comprometer o mecanismo bem elaborado de resolução de disputas.

Mas, se os países-membros da OMC reconhecem que se deve buscar, com o objetivo de um desenvolvimento sustentável, a elevação dos níveis de vida, o pleno emprego, o cumprimento de padrões trabalhistas internacionalmente reconhecidos, o crescimento econômico, a utilização ótima dos recursos mundiais, a questão que se coloca é de saber se a OMC pode trazer meios reais, de jure e de facto, de proteção à noção de desenvolvimento sustentável. $A$ priori, a resposta é negativa. Não há qualquer acordo na OMC que tenha por objetivo estabelecer direitos e obrigações em matéria de desenvolvimento sustentável. O mito de que a OMC tudo pode em razão da possibilidade de retaliação da instituição tem limites. O adágio nulla poena sine lege não deve jamais ser esquecido. Os Acordos da OMC tratam apenas de modo oblíquo da noção de desenvolvimento sustentável. Como não "há direito sem obrigação; e não há nem direito nem obrigação sem uma norma de conduta” (Bobbio, 2004:18), força é 
de constatar que a OMC não tem competência institucional para responder aos anseios de proteção jurisdicional buscados pela noção de desenvolvimento sustentável.

Entretanto, desde a entrada em vigor da OMC em 1ํ de janeiro de 1995, seus paísesmembros trazem em seus argumentos jurídicos noções relacionadas ao desenvolvimento sustentável, diante do OSC. Basta lembrar a primeira decisão proferida pelo OSC, no caso United States: standards for reformulated and conventional gasoline. Diante disso, indagamos se é, de fato, possível à OMC proteger essa universalidade de valores chamada de desenvolvimento sustentável, apesar do silêncio de seus Acordos abrangidos. Em outras palavras, se o OSC, ao examinar eventuais violações aos Acordos da OMC, pode "impor", juridicamente, aos países-membros o respeito aos conceitos de desenvolvimento sustentável, com isso estaríamos demolindo algumas barreiras e limites da OMC? Para responder a essas indagações, examinaremos, primeiramente, os argumentos relacionados a desenvolvimento sustentável presentes nas disputas que foram trazidas ao OSC pelos países-membros. Em seguida, analisaremos o tratamento dado pelo OSC aos argumentos relacionados ao desenvolvimento sustentável nas respectivas disputas. Com base nos resultados obtidos, em conclusão, sugerimos as cautelas que devem ser tomadas na implementação do conceito de desenvolvimento sustentável no âmbito da OMC.

\section{Noção de desenvolvimento sustentável}

Em 1964, André Philip ressaltou, em seu discurso na Conferência da ONU sobre o Comércio e Desenvolvimento (CNUCD), a importância do direito ao desenvolvimento (Philip, 1964:23). Mais tarde, a obra clássica, Rumo ao direito internacional do desenvolvimento, evidenciou "o hiato ora existente entre os países em vias de desenvolvimento e os desenvolvidos, [que está] destinado a crescer progressivamente, até que se promova uma transformação completa das políticas econômicas internacionais" (Virally, 1965:8). Na década de 1970, o relatório do Clube de Roma 1972, The limits of growth, alerta para a industrialização crescente, o crescimento desordenado da população mundial, a carência na produção de alimentos e a utilização exaustiva de recursos naturais, e clama para que a humanidade passe a se inquietar com os "limites de crescimento do planeta". No mesmo ano, a Conferência de Estocolmo sobre o Ambiente Humano das Nações Unidas traz um debate global, pela primeira vez, de aspectos relacionados ao meio ambiente.

Mais tarde, no relatório Our common future da Comissão Mundial sobre Meio Ambiente e Desenvolvimento (Relatório Brundtland, 1987), surge uma definição ampla e bastante flexível da noção de desenvolvimento sustentável. Our common future clama por uma transformação política levando em conta os problemas relacionados à degradação do meio ambiente paralelamente aos problemas relacionados com o desenvolvimento social e econômico. Assim, a noção de desenvolvimento sustentável é entendida como o desenvolvimento que busca responder "às necessidades atuais e presentes da humanidade; sem comprometer, contudo, as necessidades das gerações futuras" (Relatório Brundtland, 1987). E, nessa perspectiva, o "es- 
tabelecimento de condições sustentáveis de estabilidade ecológica e econômica para o futuro" passa a ser o ideal buscado por todos (Relatório Brundtland, 1987).

É fato que essa noção ampla não prima por uma clareza na sua definição e por essa razão foi e é, até hoje, bastante criticada. De qualquer modo, para Oliveira e Santos (2015:192), desenvolvimento sustentável é uma variável do processo de aproximação da condição a longo prazo de sustentabilidade. Quase no mesmo sentido, Dovers e Handmer (1992) afirmam que desenvolvimento sustentável é um caminho de mudança endógena que mantém ou aumenta o atributo de sustentabilidade, para responder às necessidades, de hoje, da população. Já para Veiga (2007:60), o desenvolvimento sustentável é a situação em que "o crescimento econômico respeita os limites da natureza em vez de destruir seus ecossistemas", oferecendo "uma chance às gerações futuras de que também possam progredir". É permitido afirmar que não há unanimidade na doutrina para uma definição de desenvolvimento sustentável, dada a complexidade do tema.

Seja como for, a adoção do Our common future pela comunidade internacional é reconhecida como o momento em que o desenvolvimento sustentável se tornou um objetivo de política global (Cordonier Segger e Khalfan, 2004:19; Schrijver e Weiss, 2004:13; Vizeu et al., 2012:574). São três as variáveis que são colocadas em evidência na elaboração do conceito de desenvolvimento sustentável pela maior parte da doutrina: os aspectos relacionados aos direitos humanos e trabalhistas; os aspectos socioeconômicos e os aspectos relacionados ao meio ambiente. Em suma: o desenvolvimento sustentável busca a melhoria da qualidade de vida da humanidade em nível global e fundamentalmente levando em conta três aspectos direitos humanos, socioeconômicos e ambientais - , para a geração presente e para as futuras gerações (United Nations, 2001; Van Bellen, 2010).

Doutrina recente proclama a emergência de um novo ramo do direito internacional, o direito internacional do desenvolvimento sustentável (French, 2005:20; Cordonier Segger e Khalfan, 2004:46; Schrijver e Weiss, 2004:13; Lowe, 2001:36; Costa, 2009:101; 2013:239). Com base nessa doutrina, o direito internacional do desenvolvimento sustentável busca proteger, no plano internacional, a integração e a adaptação de regras jurídicas para alcançar a justiça social, o desenvolvimento econômico e a proteção ambiental. Sem querer trazer à discussão a emergência ou não de um novo ramo do direito internacional, é permitido afirmar que o conceito de desenvolvimento sustentável é tratado por número cada vez maior de tratados e convenções internacionais, tanto em relação aos aspectos relacionados aos direitos humanos e trabalhistas, quanto aos aspectos socioeconômicos e aos aspectos relacionados ao meio ambiente. Não temos a intenção de mencionar aqui todos os instrumentos jurídicos, mas pensamos, particularmente, ao lado do Acordo Constitutivo da OMC, na Declaração Universal dos Direitos Humanos, na Declaração de Estocolmo da ONU sobre o Ambiente Humano de 1972, nas Convenções Fundamentais da OIT, no Pacto Internacional dos Direitos Civis e Políticos, no Pacto Internacional sobre Direitos Econômicos, Sociais e Culturais, na Declaração do Rio da ONU sobre o Meio Ambiente e Desenvolvimento de 1992, na Declaração de Johanesburgo sobre Desenvolvimento Sustentável de 2002. Esses tratados e convenções internacionais são citados e mencionados no contencioso da OMC, nas disputas trazidas pelos países-membros 
diante do OSC. É assim, com fundamento nesses instrumentos jurídicos, que se pode argumentar a presença do conceito de desenvolvimento sustentável no âmbito da OMC, apesar da inexistência de acordo específico sobre o tema.

\section{Metodologia}

A apreciação da noção de desenvolvimento sustentável na OMC é aqui examinada sob o prisma "jurisprudencial", por meio da análise das disputas trazidas ao contencioso do OSC (Yin, 1989; Eisenhardt, 1989:532). Para identificar os aspectos ligados ao desenvolvimento sustentável na dinâmica do OSC, ou seja, os aspectos relacionados ao tripé direitos humanos e trabalhistas, aspectos socioeconômicos e aspectos relacionados ao meio ambiente, foi escolhida a metodologia qualitativa, por julgarmos a mais adequada. Isto porque a verificação da frequência de aparição de fenômenos recorrentes, típica do método quantitativo, não é totalmente eficaz para a plena compreensão desses aspectos no contencioso jurídico da OMC que trata do conceito de desenvolvimento sustentável. É fato que as disputas trazidas pelos países-membros da OMC não são exatamente idênticas. Contudo, os critérios relacionados ao desenvolvimento sustentável são semelhantes, possibilitando, portanto, a utilização do estudo dos casos "jurisprudenciais" mediante o método comparativo (Collier, 1993).

Para alcançar o objetivo aqui proposto, examinamos 474 disputas submetidas ao OSC, desde a entrada em vigor da OMC em 1ํ de janeiro de 1995 até $1^{\circ}$ de janeiro de 2014. As disputas foram selecionadas a partir do site da OMC, que relaciona todas as disputas trazidas por seus países-membros, desde a entrada em vigor da instituição. As disputas que foram trazidas ao OSC mas que permanecem pendentes de resultado até $1^{\circ}$ de janeiro de 2014, ou seja, no estágio de consultas, nomeação dos panelistas ou sem a publicação de um relatório do painel, não foram consideradas, posto que não há como examinar se as partes utilizaram argumentos relacionados ao desenvolvimento sustentável nesse estágio. Num segundo momento, após examinar as 474 disputas, foram selecionadas as disputas que traziam em seus argumentos jurídicos elementos relacionados à noção de desenvolvimento sustentável. As disputas foram selecionadas e classificadas levando em conta os três tópicos fundamentais presentes na noção de desenvolvimento sustentável, a saber: proteção aos direitos humanos e trabalhistas, aspectos socioeconômicos e aspectos ambientais. Em seguida, foi realizado um exame, de forma e de conteúdo, para verificar como o OSC decidiu essas disputas em relação aos argumentos jurídicos relacionados ao desenvolvimento sustentável, posto que tais argumentos só estão presentes nos Acordos da OMC de modo oblíquo. Na maior parte dos casos trazidos ao OSC, o principal argumento em prol da noção de desenvolvimento sustentável tem como fundamento as exceções do art. XX do Acordo Gatt-94, as exceções do art. XIV do Acordo Gats e as exceções do art. 27 do Acordo Trips. Além disso, outros Acordos abrangidos podem ser citados, tais como o Acordo sobre a Aplicação de Medidas Sanitárias e Fitossanitárias e o Acordo sobre Barreiras Técnicas ao Comércio. Como já explicado, a OMC não tem, entre todos os seus Acordos abrangidos, nenhum acordo que trate especificamente de desenvolvimento sustentá- 
vel, do mesmo modo como não há nenhum acordo sobre proteção ao meio ambiente. Assim, os aspectos relacionados ao desenvolvimento sustentável trazidos pelos países-membros nas suas disputas no OSC foram feitos de modo indireto. Ao final da análise foi possível, então, averiguar a extensão da presença de elementos relacionados ao desenvolvimento sustentável no âmbito do OSC, bem como o modo como foram decididas as disputas trazidas pelos paísesmembros, relativas aos argumentos trazidos relacionados ao desenvolvimento sustentável.

\section{Desenvolvimento sustentável nas disputas trazidas ao OSC}

A dinâmica "jurisprudencial" da OMC concede ao OSC a tarefa de interpretar os Acordos da $\mathrm{OMC}$, na forma determinada pelo Entendimento Relativo às Normas e Procedimentos que Regem a Solução de Controvérsias (Entendimento). Ele representa a base do sistema de resolução de disputas da OMC. Entre suas funções, cabe ao OSC o estabelecimento dos Painéis e o monitoramento da implementação das recomendações dos Painéis e do Órgão de Apelação pelos países-membros e das retaliações ou da suspensão de concessões ou obrigações.

A prática demonstra que o OSC tem desempenhado o papel que lhe foi atribuído, de modo eficaz (Ramanzini Junior e Viana, 2012:48). Para corroborar essa afirmação, basta lembrar que 474 disputas foram submetidas ao OSC, desde a entrada em vigor da OMC em 1ำ de janeiro de 1995 até $1^{\circ}$ de janeiro de 2014. Em pouco mais de 18 anos de vida, a OMC já teve, proporcionalmente, um número maior de disputas do que o antigo Gatt, nos seus quase 50 anos de vida. Isto faz prova da confiança que os países-membros têm no sistema de resoluções de disputas da OMC.

Para averiguar a universalidade de valores que compreende a noção de desenvolvimento sustentável presente no contencioso da OMC, analisamos as 474 disputas submetidas ao OSC, desde a entrada em vigor da OMC em 1ํ de janeiro de 1995 até 1o de janeiro de 2014. Do total de 474 disputas, foram encontrados em apenas 46 delas argumentos envolvendo noções de desenvolvimento sustentável. A primeira conclusão que se impõe é que a "jurisprudência" envolvendo o tema não é representativa, perfazendo um percentual de apenas 13\% do total de disputas submetidas ao OSC.

\section{Quadro 1 \\ Relação das 46 disputas relacionadas com desenvolvimento sustentável submetidas ao OSC}

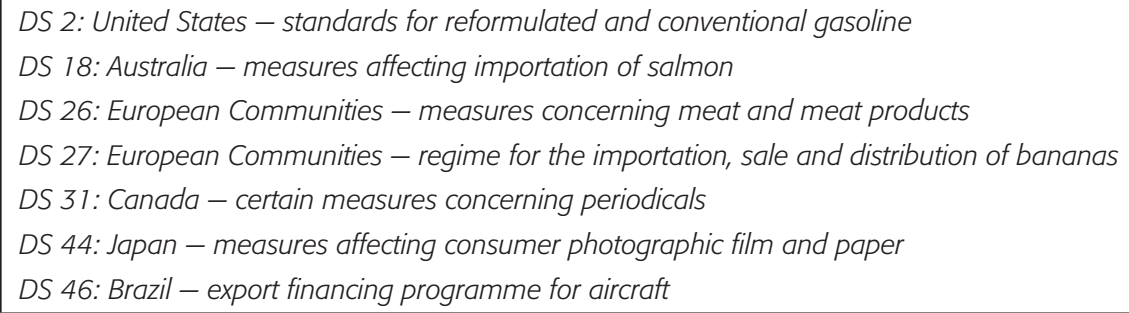


DS 50: India - patent protection for pharmaceutical and agricultural chemical products

DS 58: United States - import prohibition of certain shrimp and shrimp products

DS 60: Guatemala - anti-dumping investigation regarding portland cement from Mexico

DS 70: Canada - measures affecting the export of civilian aircraft

DS 76: Japan - measures affecting agricultural products

DS 79: India - patent protection for pharmaceutical and agricultural chemical products

DS 89: United States - anti-dumping duties on imports of colour television receivers from Korea

DS 90: India - quantitative restrictions on imports of agricultural, textile and industrial products

DS 103: Canada - measures affecting the importation of milk and the exportation of dairy products

DS 113: Canada - measures affecting dairy exports

DS 114: Canada - patent protection of pharmaceutical products

DS 132: Mexico - anti-dumping investigation of high-fructose corn syrup (hfcs) from the United States

DS 135: European Communities - measures affecting asbestos and products containing asbestos

DS 174: European Communities - protection of trademarks and geographical indications for agricultural products and foodstuffs

DS 176: United States - Section 211 omnibus appropriations Act of 1998

DS 193: Chile - measures affecting the transit and importing of swordfish

DS 236: United States - preliminary determinations with respect to certain softwood lumber from Canada

DS 245: Japan - measures affecting the importation of apples

DS 246: European Communities - conditions for the granting of tariff preferences to developing countries

DS 247: United States - provisional anti-dumping measure on imports of certain softwood lumber from Canada

DS 257: United States - final countervailing duty determination with respect to certain softwood lumber from Canada

DS 267: United States - subsidies on upland cotton

DS 290: European Communities - protection of trademarks and geographical indications for agricultural products and foodstuffs

DS 291: European Communities - measures affecting the approval and marketing of biotech products

DS 292: European Communities - measures affecting the approval and marketing of biotech products

DS 293: European Communities - measures affecting the approval and marketing of biotech products

DS 308: Mexico - tax measures on soft drinks and other beverages

DS 315: European Communities - selected customs matters

DS 320: United States - continued suspension of obligations in the EC - hormones dispute

DS 321: Canada - continued suspension of obligations in the EC - hormones dispute

DS 332: Brazil - measures affecting imports of retreaded tyres

DS 362: China - measures affecting the protection and enforcement of intellectual property rights

DS 381: United States - measures concerning the importation, marketing and sale of tuna and tuna products

DS 386: United States of America - certain country of origin labelling requirements

DS 391: Korea, Republic of - measures affecting the importation of bovine meat and meat products from Canada

DS 398: China - measures related to the exportation of various raw materials

DS 401: European Communities - measures prohibiting the importation and marketing of seal products

DS 406: United States of America - measures affecting the production and sale of clove cigarettes

DS 430: India - measures concerning the importation of certain agricultural products from the United States

Fonte: WTO (2015). 
Dessas 46 disputas, mais de 50\% delas foram propostas entre 1995 e 1999; quase 40\% das disputas foram propostas entre 2000 e 2004 e sequer $10 \%$ das disputas foram propostas entre os anos de 2005 a 2014.

$$
\text { Tabela } 1
$$

Disputas por períodos de tempo

\begin{tabular}{|lc|}
\hline \multicolumn{1}{|c|}{ Período } & № de Casos \\
\hline Casos OMC e Desenvolvimento Sustentável: 1995-99 & 23 \\
Casos OMC e Desenvolvimento Sustentável: 2000-04 & 15 \\
Casos OMC e Desenvolvimento Sustentável: 2005-14 & 8 \\
TOTAL & 46 \\
\hline
\end{tabular}

Fonte: WTO (2015). Análise dos dados realizada pela autora.

Ainda, a título ilustrativo, citamos alguns exemplos de aspectos relacionados à noção de sustentabilidade que foram encontrados nas mencionadas 46 disputas selecionadas. Lê-se no caso, United States - standards for reformulated and conventional gasoline, que "esta regra tem por objetivo proteger a saúde pública e o bem-estar através da redução da emissão de tóxicos poluentes". A proteção do meio ambiente e da saúde pública faz parte da universalidade de valores que compõem a noção de desenvolvimento sustentável. No mesmo sentido, cita-se o caso Brazil - measures affecting imports of retreaded tyres: "as autoridades do Rio Grande do Sul preocupam-se com o aumento das importações de pneus reciclados no estado e com os riscos associados ao meio ambiente e à saúde pública".

Os argumentos jurídicos estão, portanto, relacionados a dois tópicos da noção de desenvolvimento sustentável: proteção aos direitos humanos e trabalhistas e aspectos ambientais.

Vale destacar, também, o caso United States - import prohibition of certain shrimp and shrimp products. O Painel, ao ressaltar o "objetivo do desenvolvimento sustentável” e sua relação com o meio ambiente, diz que esse objetivo está expresso, explicitamente, no Preâmbulo do Acordo Constitutivo da OMC. O OSC ressalta ainda, num dictum, que: "segundo o Artigo XX (e), um signatário pode proibir ou de outro modo regulamentar o comércio de produtos realizados em prisões. Este caso, uma forma específica de exploração do trabalho, é alvo de tratamento especial no GATT".

Ainda, relacionado à proteção dos direitos humanos e do meio ambiente, citamos o caso Brazil - export financing programme for aircraft: “(...) financiando aeronaves ou outros produtos que são 'amigos-aliados do meio ambiente' ou são feitos por meio de padrões trabalhistas 'justos' [fair]". No mesmo sentido em relação à proteção aos direitos humanos e ao meio ambiente, podemos mencionar outros casos semelhantes, a saber: Australia - measures affecting importation of salmon, European Communities - measures concerning meat and meat products, United States - Import prohibition of certain shrimp and shrimp products, Chile - 
provisional safeguard measure on certain milk products, European Communities - measures affecting the approval and marketing of biotech products e European Communities - measures affecting asbestos and products containing asbestos.

Em relação aos direitos humanos e trabalhistas e socioeconômicos, o "leading case" que foi objeto de exame pelo OSC é India - quantitative restrictions on imports of agricultural, textile and industrial products. Nessa disputa se pode constatar a preocupação com o "(...) impacto nos salários e no emprego e, portanto, ceteris paribus, na pobreza também”, em decorrência da medida comercial em litígio. Outras disputas podem ser trazidas à colação. No caso European Communities - conditions for the granting of tariff preferences to developing countries se pode ler na decisão do Órgão de Apelação que: "De acordo com a Comunidade Andina, estas são consequências socioeconômicas muito bem documentadas pelo maior doador mundial de auxílio internacional, pelas agências de desenvolvimento e pelas organizações de direitos humanos".

No mesmo sentido dos dois litígios anteriores, o caso European Communities - selected customs matters.

Ainda, cita-se o caso European Communities — protection of trademarks and geographical indications for agricultural products and foodstuffs:

Membros podem, ao formular e alterar suas legislações e regulamentações, adotar medidas necessárias à proteção da saúde e da nutrição, e promover o interesse público em setores de vital importância para seu desenvolvimento socioeconômico e tecnológico, desde que tais medidas sejam consistentes com as disposições deste Acordo.

Levando em conta apenas o aspecto ambiental, o caso China - measures related to the exportation of various raw materials ressalta que:

a China alegou, em sua defesa, que as quotas e taxas de exportação eram justificadas para a conservação de recursos naturais exauríveis, para algumas matérias primas. Mas, a China não foi capaz de demonstrar que impõe essas restrições à produção ou ao consumo local.

No mesmo sentido, cita-se o caso Chile - measures affecting the transit and importing of swordfish:

Chile e as Comunidades Europeias lançarão uma iniciativa conjunta (...), para a qual serão convidadas todas as partes interessadas na indústria da pesca, para promover a cooperação multilateral para a conservação e gerenciamento desses estoques durante todo o período de variação migratória.

Apesar das preocupações ambientais alegadas em ambas as disputas, bem como a série de menções aos tratados e convenções internacionais em matéria ambiental pelas partes, o 
fato é que as medidas em litígio tinham um cunho, pura e simplesmente, protecionista e não tinham por objetivo real a proteção ao meio ambiente e aos recursos naturais exauríveis e ao desenvolvimento sustentável como fim último.

Já em relação aos aspectos socioeconômicos relacionados ao desenvolvimento sustentável, vários casos foram trazidos ao OSC. Entre eles, cita-se o caso European Communities - regime for the importation, sale and distribution of bananas. Nos argumentos apresentados neste contencioso, lê-se que:

era essencial para as economias emergentes manter oportunidades futuras de comércio, mesmo antes que as "potencialidades" se tornem aparentes. De outra forma, oportunidades de promoção de comércio e desenvolvimento poderiam estar para sempre limitadas ou excluídas.

\section{(...)}

A indústria da banana é a maior fonte de receitas externas e emprega uma porção significativa da população nicaraguense.

Como o conceito de sustentabilidade engloba, num tripé, fenômenos relacionados aos direitos humanos de terceira geração, aos aspectos ambientais e aos socioeconômicos, esses fenômenos aparecem, concomitantemente, na maior parte das 46 disputas selecionadas. Na maioria das disputas examinadas, foi possível constatar que mais de um fenômeno relacionado à noção de sustentabilidade era mencionado nos argumentos das partes em litígio. Assim, no mesmo litígio, as partes traziam argumentos relacionados ao meio ambiente, assim como à proteção aos direitos humanos e trabalhistas (saúde pública ou da vida animal). Como exemplo, lembramos os casos citados United States - standards for reformulated and conventional gasoline e Brazil - measures affecting imports of retreaded tyres. Ou ainda, no mesmo litígio, encontrávamos referência ao desenvolvimento econômico atrelado à proteção ambiental, como nos casos citados Brazil - export financing programme for aircraft e United States - import prohibition of certain shrimp and shrimp products. E, assim, sucessivamente. Poucos foram os casos que tratavam apenas de um dos argumentos do tripé de base da noção de desenvolvimento sustentável. Com esse resultado, se pode afirmar que a noção de desenvolvimento sustentável reúne, de fato, num amálgama singular, justiça social, distribuição de renda, capacidade tecnológica, pleno emprego, ambiente de trabalho seguro e saudável, cuidado com o meio ambiente e o bem-estar socioeconômico.

Em síntese, das 474 disputas submetidas ao OSC, até 1ํ de janeiro de 2014, apenas 46 disputas traziam argumentos envolvendo desenvolvimento sustentável. Para demonstrar as menções relativas à sustentabilidade nessas disputas, ilustramos, brevemente, os resultados encontrados (quadro 2). Assim, é possível, a seguir, examinar a forma como essas disputas foram decididas pelo OSC, diante dos argumentos relacionados à noção de sustentabilidade. 


\section{Quadro 2 \\ Exemplos de referências ao desenvolvimento sustentável presentes em algumas disputas selecionadas}

\begin{tabular}{|c|c|c|}
\hline № & Nome do Caso & Ilustração \\
\hline DS 18 & $\begin{array}{l}\text { Australia - measures affecting importation } \\
\text { of salmon }\end{array}$ & $\begin{array}{l}\text { "Membros devem assegurar que as medidas sanitárias ou fitossanitárias } \\
\text { sejam aplicadas apenas para proteger a vida e a saúde humana, anima } \\
\text { ou vegetal, e sejam baseadas em princípios científicos e não sejam } \\
\text { mantidas sem evidência científica suficiente" }\end{array}$ \\
\hline DS 31 & $\begin{array}{l}\text { Canada - certain measures concerning } \\
\text { periodicals }\end{array}$ & $\begin{array}{l}\text { "a capacidade de um Membro de tomar medidas para proteção da } \\
\text { identidade cultural não é um argumento neste caso (...) é intenção do } \\
\text { Canadá continuar a perseguir seus objetivos de política cultural" }\end{array}$ \\
\hline DS 44 & $\begin{array}{l}\text { Japan - measures affecting consumer } \\
\text { photographic film and paper }\end{array}$ & $\begin{array}{l}\text { "o relatório enumera os objetivos da política de distribuição (...) como } \\
\text { (iii) assegurar força de trabalho e educação aos empregados" }\end{array}$ \\
\hline DS 50 & $\begin{array}{l}\text { India - patent protection for pharmaceutical } \\
\text { and agricultural chemical products }\end{array}$ & $\begin{array}{l}\text { "Artigo } 19 \text { da Declaração Universal dos Direitos do Homem declara que } \\
\text { todos têm direito à liberdade de opinião e expressão 'independentemente } \\
\text { de fronteiras' (...), Artigo } 11 \text { do Pacto Internacional dos Direitos Civis e } \\
\text { Políticos estabelece que ninguém será preso baseado na incapacidade } \\
\text { de cumprir obrigações contratuais" }\end{array}$ \\
\hline DS 114 & $\begin{array}{l}\text { Canada - patent protection of } \\
\text { pharmaceutical products }\end{array}$ & $\begin{array}{l}\text { "A legitimidade das medidas para promoção do uso de medicamentos } \\
\text { genéricos, como forma de proteção da saúde pública, foi endossada pela } \\
\text { Organização Mundial da Saúde (OMS)." }\end{array}$ \\
\hline DS 176 & $\begin{array}{l}\text { United States - Section } 211 \text { omnibus } \\
\text { appropriations Act of } 1998\end{array}$ & $\begin{array}{l}\text { "De acordo com o Artigo } 17 \text { da DUDH, 'Toda pessoa tem direito } \\
\text { à propriedade, só ou em sociedade com outros. Ninguém será } \\
\text { arbitrariamente privado de sua propriedade'. Disposição similar encontra- } \\
\text { se, inter alia, na Declaração Americana de Direitos do Homem e no } \\
\text { PIDESC das Nações Unidas" }\end{array}$ \\
\hline DS 245 & $\begin{array}{l}\text { Japan - measures affecting the importation } \\
\text { of apples }\end{array}$ & $\begin{array}{l}\text { "O processo PRA pode ser dividido em três passos inter-relacionados } \\
\text { categorização da peste, avaliação de probabilidade e de disseminação } \\
\text { e avaliação de consequências econômicas potenciais (incluindo impacto } \\
\text { ambiental)" }\end{array}$ \\
\hline DS 267 & United States - subsidies on upland cotton & $\begin{array}{l}\text { "Não é economicamente sustentável plantar algodão em terra não } \\
\text { apropriada ao cultivo do algodão." }\end{array}$ \\
\hline DS 290 & $\begin{array}{l}\text { European Communities - protection of } \\
\text { trademarks and geographical indications } \\
\text { for agricultural products and foodstuffs }\end{array}$ & $\begin{array}{l}\text { "o Acordo TRIPS - Artigo } 7 \text { - reconhece expressamente que proteção e } \\
\text { o cumprimento dos direitos de propriedade intelectual devem ser feitos } \\
\text { 'de modo a conduzir bem-estar social e econômico'" }\end{array}$ \\
\hline DS 291 & $\begin{array}{l}\text { European Communities - measures } \\
\text { affecting the approval and marketing of } \\
\text { biotech products }\end{array}$ & $\begin{array}{l}\text { "Ademais, os riscos à vida ou saúde humana, animal e vegetal são } \\
\text { componentes singulares (mas apenas componentes) do risco global maior } \\
\text { para a conservação e sustentabilidade da utilização da diversidade biológica" }\end{array}$ \\
\hline DS 308 & $\begin{array}{l}\text { Mexico - tax measures on soft drinks and } \\
\text { other beverages }\end{array}$ & $\begin{array}{l}\text { "Além disso, a necessidade de tais esforços foi reconhecida pela própria } \\
\text { OMC, bem como por número significativo de instrumentos e declarações } \\
\text { internacionais. Por exemplo, o Princípio } 12 \text { da Declaração do Rio diz que } \\
\text { medidas ambientais dirigidas a problemas ambientais transfronteiriços ou } \\
\text { globais devem, se possível, estar baseadas no consenso internacional" }\end{array}$ \\
\hline
\end{tabular}




\begin{tabular}{|c|c|c|}
\hline № & Nome do Caso & Ilustração \\
\hline DS 362 & $\begin{array}{l}\text { China - measures affecting the protection } \\
\text { and enforcement of intellectual property } \\
\text { rights }\end{array}$ & $\begin{array}{l}\text { "(...) deve ser ressaltado que o Acordo TRIPS considera como um objetivo } \\
\text { essencial, não apenas o cumprimento de aspectos de comércio do } \\
\text { direito da propriedade intelectual, mas também a realização de outros } \\
\text { temas; tais como a necessidade de melhoria dos padrões de vida dos } \\
\text { Membros, especialmente os de menor desenvolvimento relativo, com } \\
\text { atenção especial às preocupações com a saúde pública e a nutrição" }\end{array}$ \\
\hline DS 381 & $\begin{array}{l}\text { United States - measures concerning the } \\
\text { importation, marketing and sale of tuna } \\
\text { and tuna products }\end{array}$ & $\begin{array}{l}\text { "México sustenta que a medida dos EUA tem por efeito proibir a } \\
\text { etiquetagem do atum mexicano com a etiquetagem 'protege-golfinhos', } \\
\text { mesmo quando o atum foi pescado por meios que atendem ao } \\
\text { padrão multilateral 'protege-golfinhos', estabelecido pela Comissão } \\
\text { Interamericana de Atum Tropical, enquanto produtos feitos de atum } \\
\text { originários de muitos outros países, inclusive os Estados Unidos, estão } \\
\text { autorizados a etiquetar como 'protege-golfinhos"' }\end{array}$ \\
\hline DS 391 & $\begin{array}{l}\text { Korea, Republic of - measures affecting } \\
\text { the importation of bovine meat and meat } \\
\text { products from Canada }\end{array}$ & $\begin{array}{l}\text { "O Artigo 2.2. do Acordo sobre Aplicação de Medidas Sanitárias e } \\
\text { Fitossanitárias determina que medidas devem ser aplicadas somente } \\
\text { na extensão necessária à proteção da vida e da saúde, as medidas não } \\
\text { estão baseadas em evidência científica e elas são mantidas sem uma } \\
\text { prova científica adequada" }\end{array}$ \\
\hline
\end{tabular}

Fonte: WTO (2015). Seleção de parte dos textos realizada pela autora.

\section{OSC diante do conceito de desenvolvimento sustentável}

Ao examinarmos a forma como foram apreciados, pelo OSC, os argumentos de sustentabilidade presentes nas 46 disputas selecionadas, ficou patente o respeito desse órgão à regra de ouro: a OMC punirá os países-membros somente diante da presença de procedimentos discriminatórios que levem a obstaculizar o comércio mundial, e desde que tais procedimentos estejam previstos em seus Acordos. Das 46 disputas examinadas, somente uma delas tinha relação efetiva com o anseio real e efetivo de proteger aspectos relacionados ao desenvolvimento sustentável. É o que se observou no caso European Communities - measures affecting asbestos and asbestos-containing products. $\mathrm{O}$ argumento relacionado ao desenvolvimento sustentável, que permitia a aplicação da exceção prevista no art. XX do GATT-94, era um argumento real e verdadeiro e merecia, portanto, proteção.

Assim, o OSC, no caso European Communities - measures affecting asbestos and asbestos-containing products, lembrou que o "Artigo XX (b) seria privado de seu effet utile se suas disposições não servissem para permitir a um Membro 'adotar e implementar medidas necessárias à proteção humana, à vida ou saúde"'. E concluiu que a:

avaliação dos evidentes riscos à saúde oriundos das propriedades físicas do produto permite que uma medida inconsistente com o Artigo III:4 seja justificada pelo Artigo XX (b) (...). No caso, o objetivo buscado pela medida é a preservação da vida humana e da saúde através da eliminação ou redução (...) de asbestos. O valor buscado tão vital quanto importante. 
A exceção da letra "b" do art. XX do Gatt-94 foi plenamente acatada pelo OSC. Logo, a proteção aos argumentos relacionados ao desenvolvimento sustentável é possível no âmbito da OMC e em respeito aos Acordos da OMC. E esse contencioso põe em xeque uma sanção outra que a condenação moral, em conformidade com os Acordos da OMC. Há um caminho que foi trilhado pelo OSC em favor dessa proteção por meio da recomendação dada no caso European Communities - measures affecting asbestos and asbestos-containing products. É nesse sentido que o contencioso da OMC pode proteger aspectos relacionados ao desenvolvimento sustentável no comércio internacional.

Já em relação aos demais 45 casos examinados, nenhum deles tinha, de fato, como razão de ser a proteção da universalidade de valores que compõem o conceito de desenvolvimento sustentável. O argumento "sustentabilidade" era trazido para o OSC, mas este não tinha real conexão com o efeito da medida discriminatória, sendo, na verdade, uma forma disfarçada de obstaculizar o comércio internacional.

Ressalte-se, ainda, que ao compararmos o número de disputas relacionadas ao desenvolvimento sustentável quando da entrada em vigor da OMC, em 1o de janeiro de 1995 até os dias de hoje, fica claro que o número de disputas diminuiu, com o passar dos anos. Isso não significa que os países-membros passaram a ter uma preocupação menor com os aspectos relacionados ao desenvolvimento sustentável mais recentemente. O que ocorreu de fato é que, quando a OMC entrou em vigor, seus países-membros resolveram testar o mecanismo do OSC e verificar até que ponto a OMC protegeria, no âmbito de seus Acordos, o conceito de desenvolvimento sustentável. Quase todas as disputas que trouxeram aspectos relacionados ao desenvolvimento sustentável nada mais eram do que medidas discriminatórias disfarçadas em "sustentabilidade". O mito da força da retaliação da OMC tem limites e barreiras, os quais são ditados pelos seus Acordos. Em caso de violação aos seus Acordos, o mecanismo do OSC pode proteger os países-membros. Caso contrário, diante de medidas disfarçadas de proteção aos aspectos relacionados ao desenvolvimento sustentável, a OMC mostrou que não dará qualquer proteção. Assim, testado o mecanismo pelos países-membros, o número de disputas relacionadas ao desenvolvimento sustentável decresceu com o decorrer do tempo.

\section{Conclusão}

No contexto mundial de nossos dias, a OMC tem papel importante a desempenhar. Tal afirmação dispensa maiores explanações. A noção de desenvolvimento sustentável abrange os mais diversos aspectos da vida humana. Ela está presente em inúmeros tratados e convenções internacionais, inclusive no âmbito da OMC, com um total de 155 disposições específicas, constantes de seus Acordos, dirigidas aos problemas crônicos de desenvolvimento da maior parte de seus países-membros.

Quando uma organização internacional é criada, o primeiro passo dado pelos seus fundadores é o de verificar o que eles podem fazer por ela. Em seguida, eles verificam o que a organização pode fazer por eles. O que a OMC pode fazer por seus países-membros para pro- 
teger o desenvolvimento sustentável, no âmbito de seu sistema de solução de controvérsias? O alargamento do âmbito de aplicação dos Acordos da OMC para abranger, de jure e de facto, o desenvolvimento sustentável necessita cuidados, apesar das boas intenções em fazê-lo. Muitos sustentam a necessidade de uma mudança de paradigma no cenário do comércio internacional, tendo a OMC papel preponderante na implementação do conceito de desenvolvimento sustentável. Não podemos esquecer, contudo, que os "dentes" da OMC só podem "morder" em presença de violação aos seus Acordos, refletida em procedimentos discriminatórios que levem a obstaculizar o comércio mundial.

Pois bem, do total de casos da OMC examinados, apenas 46 deles mencionam argumentos relacionados ao desenvolvimento sustentável. Trata-se de percentual um pouco superior a $10 \%$ do total de litígios da OMC. Do exame desses litígios, é possível concluir que a noção de desenvolvimento sustentável é tratada apenas obliquamente, pois ela não corresponde ao fim último da medida discriminatória pretendida. Não é, contudo, despropositado afirmar, diante da decisão proferida no caso European Communities - measures affecting asbestos and asbestos-containing products, que o conceito de sustentabilidade pode ser protegido pela OMC; mas desde que esteja refletido de fato em seus Acordos. Diante disso, é importante que os países-membros da OMC reconheçam as limitações da instituição e consigam alcançar uma agenda comum que dê suporte à noção de desenvolvimento sustentável na liberalização do comércio internacional. É certo que a exequibilidade de aspectos relacionados ao desenvolvimento sustentável causa desconforto entre os paísesmembros, além de inúmeras controvérsias. Mas o desenvolvimento sustentável veio para ficar. Uma opção realista para combater as medidas protecionistas que clamam pela proteção de aspectos relacionados ao desenvolvimento sustentável, mas que na verdade nada mais são do que medidas discriminatórias disfarçadas, é por meio de uma declaração ministerial, que sirva como base e guia de conduta e de interpretação para o OSC e para o sistema da OMC como um todo.

O exame do contencioso da OMC não deve ser abandonado. No futuro, outros aspectos podem ser levados em conta, com base na pesquisa já realizada. Por exemplo, (i) averiguar a participação dos países latino-americanos no contencioso da OMC relacionado ao desenvolvimento sustentável, ou (ii) verificar, dentro de alguns anos, a participação dos países Bric (Brasil, Rússia, Índia e China) no contencioso da OMC, posto que hoje o contencioso da Rússia é praticamente inexistente, em razão de sua recente ascensão à OMC. Por fim, este trabalho de pesquisa pode ser útil, também, como forma de apoio à emergência de um novo ramo do direito internacional, mediante a presença de elementos do direito internacional do desenvolvimento sustentável no contencioso de uma organização internacional com o peso da OMC, se demonstra que sustentabilidade é um tema relevante na agenda internacional, embora seu uso, na grande maioria dos casos, tenha sido feito pelos países-membros da OMC como um obstáculo "legítimo" ao comércio mundial e não como forma de desenvolvimento que procure responder às necessidades atuais e presentes da humanidade; sem comprometer, contudo, as necessidades das futuras gerações. 


\section{Referências}

ACORDO CONSTITUTIVO DA ORGANIZAÇÃO MUNDIAL DO COMÉRCIO. Disponível em: <www. mdic.gov.br/arquivo/secex/omc/acordos/portugues/02estabeleceomc.pdf > ; <www.wto.org/ english/docs_e/legal_e/04-wto_e.htm\#articleI>. Acesso em: 25 fev. 2015.

AMARAL JÚNIOR, Alberto do (Org.). OMC e o comércio internacional. São Paulo: Aduaneiras, 2002.

BAPTISTA, Luiz Olavo. O direito é história - Alocução de abertura. In: CONFERÊNCIA DO INSTITUTO DE DIREITO DO COMÉRCIO INTERNACIONAL E DESENVOLVIMENTO, São Paulo. 10 ANOS de OMC. Uma análise do sistema de solução de controvérsias e perspectivas. São Paulo: Aduaneiras, 2007. p. 13-22.

BEZERRA DE MELO, Paulo Thiago N. Indicadores da dimensão institucional do desenvolvimento sustentável e os objetivos da Rio +20. Desenvolvimento em Questão, n. 23, p. 74-117, maio/ago. 2013. BOBBIO, Norberto. A era dos direitos. 9. ed. Rio de Janeiro: Campus; Elsevier, 2004.

CESAR, Susan Elizabeth M.; SATO, Eiiti. A Rodada Doha, as mudanças no regime do comércio internacional e a política comercial brasileira. Revista Brasileira de Política Internacional, Brasília, v. 55, n. 1, p. 174-193, 2012. Disponível em: <http://www.scielo.br/scielo.php?script=sci_arttext\&pid=S0034-73292012000100010\&lng =pt\&nrm=iso > . Acesso em: 25 fev. 2015.

COLLIER, David. The comparative method. In: FINIFTER, Ada W. (Ed.). Political science: the state of the discipline. Washington, DC: American Political Science Association, 1993. p. 105-119.

CORDONIER SEGGER, Marie-Claire; KHALFAN, Ashfaq. Sustainable development law: principles, practices \& prospects. Oxford: Oxford University Press, 2004.

COSTA, Ligia Maura. Comércio exterior. Negociação e aspectos legais. Rio de Janeiro: Elsevier, 2005. COSTA, Ligia Maura. Direito internacional do desenvolvimento sustentável e os códigos de conduta de responsabilidade social. Análise do Setor do Gás e Petróleo. Curitiba: Juruá, 2009.

COSTA, Ligia Maura. OMC e direito internacional do desenvolvimento sustentável. São Paulo: Quartier Latin, 2013.

DECLARAÇÃO DE ESTOCOLMO DA ONU SOBRE O AMBIENTE HUMANO, 1972. Disponível em: <www.silex.com.br/leis/normas/estocolmo.htm>. Acesso em: 25 fev. 2015.

DOVERS, Stephen R.; HANDMER, John. Uncertainty, sustainability and change. Global Environ Change, v. 4, n. 2, p. 262-276, 1992.

DS 2. United States - standards for reformulated and conventional gasoline. WT/DS2/AB/R. Disponível em: <www.wto.org/english/tratop_e/dispu_e/cases_e/ds2_e.htm >. Acesso em: 25 fev. 2015.

DS 18. Australia - measures affecting importation of salmon. WT/DS18/AB/R. Disponível em: <www.wto.org/english/tratop_e/dispu_e/cases_e/ds18_e.htm >. Acesso em: 25 fev. 2015. 
DS 26. European Communities - measures concerning meat and meat products. WT/DS27/AB/R. Disponível em: <www.wto.org/english/tratop_e/dispu_e/cases_e/ds27_e.htm>. Acesso em: 25 fev. 2015.

DS 27. European Communities - regime for the importation, sale and distribution of bananas. WT/DS27/AB/R. Disponível em: <www.wto.org/english/tratop_e/dispu_e/cases_e/ds27_e.htm>. Acesso em: 25 fev. 2015.

DS 31. Canada — certain measures concerning periodicals. WT/DS31/AB/R. Disponível em: <www. wto.org/english/tratop_e/dispu_e/cases_e/ds31_e.htm>. Acesso em: 25 fev. 2015.

DS 44. Japan - measures affecting consumer photographic film and paper. WT/DS44/AB/R. Disponível em: <www.wto.org/english/tratop_e/dispu_e/cases_e/ds44_e.htm > . Acesso em: 25 fev. 2015.

DS 46. Brazil - export financing programme for aircraft. WT/DS46/AB/R. Disponível em: <www. wto.org/english/tratop_e/dispu_e/cases_e/ds46_e.htm>. Acesso em: 25 fev. 2015.

DS 50. India - patent protection for pharmaceutical and agricultural chemical products. WT/ DS50/AB/R. Disponível em: <www.wto.org/english/tratop_e/dispu_e/cases_e/ds50_e.htm>. Acesso em: 25 fev. 2015.

DS 58. United States - import prohibition of certain shrimp and shrimp products. WT/DS58/AB/R. Disponível em: <www.wto.org/english/tratop_e/dispu_e/58abr.doc>. Acesso em: 25 fev. 2015.

DS 60. Guatemala - Anti-dumping investigation regarding portland cement from Mexico. WT/ DS60/AB/R. Disponível em: <www.wto.org/english/tratop_e/dispu_e/cases_e/ds60_e.htm>. Acesso em: 25 fev. 2015.

DS 70: Canada - measures affecting the export of civilian aircraft. WT/DS70/AB/R. Disponível em: <www.wto.org/english/tratop_e/dispu_e/cases_e/ds70_e.htm>. Acesso em: 25 fev. 2015.

DS 76. Japan — measures affecting agricultural products. WT/DS76/AB/R. Disponível em: <www. wto.org/english/tratop_e/dispu_e/cases_e/ds76_e.htm>. Acesso em: 25 fev. 2015.

DS 79. India - patent protection for pharmaceutical and agricultural chemical products. WT/ DS79/R. Disponível em: <www.wto.org/english/tratop_e/dispu_e/cases_e/ds79_e.htm>.Acesso em: 25 fev. 2015.

DS 89. United States - Anti-dumping duties on imports of colour television receivers from Korea. WT/DS89/AB/R. Disponível em: <www.wto.org/english/tratop_e/dispu_e/cases_e/ds89_e.htm>. Acesso em: 25 fev. 2015.

DS 90. India - quantitative restrictions on imports of agricultural, textile and industrial products. WT/DS90/AB/R. Disponível em: <www.wto.org/english/tratop_e/dispu_e/cases_e/ds90_e.htm>. Acesso em: 25 fev. 2015.

DS 103. Canada - measures affecting the importation of milk and the exportation of dairy products. WT/DS103/AB/R. Disponível em: <www.wto.org/english/tratop_e/dispu_e/cases_e/ds103_e. htm >. Acesso em: 25 fev. 2015. 
DS 113. Canada - measures affecting dairy exports. WT/DS113/AB/R. Disponível em: <www. wto.org/english/tratop_e/dispu_e/cases_e/ds113_e.htm>. Acesso em: 25 fev. 2015.

DS 114. Canada - patent protection of pharmaceutical products. WT/DS114/AB/R. Disponível em: <www.wto.org/english/tratop_e/dispu_e/cases_e/ds114_e.htm > . Acesso em: 25 fev. 2015.

DS 132. Mexico - Anti-dumping investigation of high-fructose corn syrup (hfcs) from the United States. WT/DS132/AB/R. Disponível em: <www.wto.org/english/tratop_e/dispu_e/cases_e/ ds132_e.htm>. Acesso em: 25 fev. 2015.

DS 135. Affecting asbestos and products containing asbestos. WT/DS135/AB/R. Disponível em: <www.wto.org/english/tratop_e/dispu_e/cases_e/ds135_e.htm>. Acesso em: 25 fev. 2015.

DS 174. European Communities - protection of trademarks and geographical indications for agricultural products and foodstuffs. WT/DS174/R. Disponível em: <www.wto.org/english/tratop_e/ dispu_e/cases_e/ds174_e.htm>. Acesso em: 25 fev. 2015.

DS 176. United States - Section 211 omnibus appropriations Act of 1998. WT/DS176/AB/R. Disponível em: <www.wto.org/english/tratop_e/dispu_e/cases_e/ds176_e.htm>. Acesso em: 25 fev. 2015.

DS 193. Chile - Measures affecting the transit and importing of swordfish. WT/DS193/AB/R. Disponível em: <www.wto.org/english/tratop_e/dispu_e/cases_e/ds193_e.htm>. Acesso em: 25 fev. 2015.

DS 236. United States - preliminary determinations with respect to certain softwood lumber from Canada.WT/DS236/R. Disponível em: <www.wto.org/english/tratop_e/dispu_e/cases_e/ds236_e. htm>. Acesso em: 25 fev. 2015.

DS 245. Japan - Measures affecting the importation of apples. WT/DS245/AB/R. Disponível em: <www.wto.org/english/tratop_e/dispu_e/cases_e/ds245_e.htm>. Acesso em: 25 fev. 2015.

DS 246. European Communities - conditions for the granting of tariff preferences to developing countries. WT/DS246/AB/R. Disponível em: <www.wto.org/english/tratop_e/dispu_e/cases_e/ ds246_e.htm>. Acesso em: 25 fev. 2015.

DS 247. United States - provisional anti-dumping measure on imports of certain softwood lumber from Canada. WT/DS247/AB/R. Disponível em: <www.wto.org/english/tratop_e/dispu_e/cases_e/ ds247_e.htm>. Acesso em: 25 fev. 2015.

DS 257. United States - final countervailing duty determination with respect to certain softwood lumber from Canada. WT/DS257/AB/R. Disponível em: <www.wto.org/english/tratop_e/dispu_e/ cases_e/ds257_e.htm>. Acesso em: 25 fev. 2015.

DS 267. United States - subsidies on upland cotton. WT/DS267/AB/R. Disponível em: <www. wto.org/english/tratop_e/dispu_e/cases_e/ds267_e.htm>. Acesso em: 25 fev. 2015.

DS 290. European Communities - protection of trademarks and geographical indications for agricultural products and foodstuffs. WT/DS290/R. Disponível em: <www.wto.org/english/tratop_e/ dispu_e/cases_e/ds290_e.htm >. Acesso em: 25 fev. 2015. 
DS 291. European Communities - measures affecting the approval and marketing of biotech products. WT/DS291/R. Disponível em: <www.wto.org/english/tratop_e/dispu_e/cases_e/ds291_e. htm>. Acesso em: 25 fev. 2015.

DS 292. European Communities - measures affecting the approval and marketing of biotech products. WT/DS292/R. Disponível em: <www.wto.org/english/tratop_e/dispu_e/cases_e/ds292_e. htm>. Acesso em: 25 fev. 2015.

DS 293. European Communities - measures affecting the approval and marketing of biotech products. WT/DS293/R. Disponível em: <www.wto.org/english/tratop_e/dispu_e/cases_e/ds293_e. htm>. Acesso em: 25 fev. 2015.

DS 308. Mexico - Tax measures on soft drinks and other beverages. WT/DS308/AB/R. Disponível em: <www.wto.org/english/tratop_e/dispu_e/cases_e/ds308_e.htm>. Acesso em: 25 fev. 2015.

DS 315. European Communities - selected customs matters. WT/DS315/AB/R. Disponível em: <www.wto.org/english/tratop_e/dispu_e/cases_e/ds315_e.htm>. Acesso em: 25 fev. 2015.

DS 320. United States - continued suspension of obligations in the EC - hormones dispute. WT/ DS320/AB/R. Disponível em: <www.wto.org/english/tratop_e/dispu_e/cases_e/ds320_e.htm>. Acesso em: 25 fev. 2015.

DS 321. Canada - continued suspension of obligations in the EC — hormones dispute. WT/DS321/ AB/R. Disponível em: <www.wto.org/english/tratop_e/dispu_e/cases_e/ds321_e.htm>. Acesso em: 25 fev. 2015.

DS 332. Brazil - measures affecting imports of retreaded tyres. WT/DS332/AB/R. Disponível em: <www.wto.org/english/tratop_e/dispu_e/cases_e/ds332_e.htm>. Acesso em: 25 fev. 2015.

DS 351. Chile - provisional safeguard measure on certain milk products. WT/DS351/AB/R. Disponível em: <www.wto.org/english/tratop_e/dispu_e/cases_e/ds351_e.htm>. Acesso em: 25 fev. 2015.

DS 362. China - measures affecting the protection and enforcement of intellectual property rights. WT/DS362/R. Disponível em: <www.wto.org/english/tratop_e/dispu_e/cases_e/ds362_e.htm>. Acesso em: 25 fev. 2015.

DS 381. United States - measures concerning the importation, marketing and sale of tuna and tuna products. WT/DS381/AB/R. Disponível em: <www.wto.org/english/tratop_e/dispu_e/cases_e/ ds381_e.htm>. Acesso em: 25 fev. 2015.

DS 386. United States of America - certain country of origin labelling requirements. WT/DS386/ AB/R. Disponível em: <www.wto.org/english/tratop_e/dispu_e/cases_e/ds386_e.htm>. Acesso em: 25 fev. 2015.

DS 389. European Communities - certain measures affecting poultry meat and poultry meat products from the United States. WT/DS389/AB/R. Disponível em: <www.wto.org/english/tratop_e/ dispu_e/cases_e/ds389_e.htm>. Acesso em: 25 fev. 2015.

DS 391. Korea, Republic of - measures affecting the importation of bovine meat and meat products from Canada. WT/DS391/AB/R. Disponível em: <www.wto.org/english/tratop_e/dispu_e/ cases_e/ds391_e.htm>. Acesso em: 25 fev. 2015. 
DS 398: China - Measures related to the exportation of various raw materials. WT/DS398/AB/R. Disponível em: <www.wto.org/english/tratop_e/dispu_e/cases_e/ds398_e.htm>. Acesso em: 25 fev. 2015.

DS 401: European Communities - measures prohibiting the importation and marketing of seal products. WT/DS401/AB/R. Disponível em: <www.wto.org/english/tratop_e/dispu_e/cases_e/ ds401_e.htm>. Acesso em: 25 fev. 2015.

DS 406: United States of America - measures affecting the production and sale of clove cigarettes. WT/DS406/AB/R. Disponível em: <www.wto.org/english/tratop_e/dispu_e/cases_e/ds406_e. htm.> Acesso em: 25 fev. 2015.

DS 430: India - measures concerning the importation of certain agricultural products from the United States. WT/DS430/AB/R. Disponível em: <www.wto.org/english/tratop_e/dispu_e/cases_e/ ds430_e.htm >. Acesso em: 25 fev. 2015.

EISENHARDT, Kathleen M. Building theories from case study research. The academy of management review, v. 14, n. 4, p. 532-550, 1989.

ENTENDIMENTO RELATIVO ÀS NORMAS E PROCEDIMENTOS QUE REGEM A SOLUÇÃO DE CONTROVÉRSIAS. Disponível em: <www.wto.org/english/docs_e/legal_e/28-dsu_e.htm>. Acesso em: 25 fev. 2015.

FAINI, Riccardo; GRILLI, Enzo R. (Ed.). Multilateralism and regionalism after the Uruguay round. Nova York: St. Martin's Press; Londres: Macmillan Press, 1997.

FLORY, Thiébaut. L'Organisation Mondiale du Commerce: droit institutionnel et substantiel. Bruxelles: Bruylant, 1999.

FRENCH, Duncan. International law and policy of sustainable development. Manchester: Manchester University Press, 2005.

HUDEC, Robert E. The adequacy of WTO dispute settlement remedies. In: HOEKMAN, Bernard; MATTOO, Aaditya; ENGLISH, Philip (Ed.). Development, trade and the WTO. A handbook. Washington: The World Bank, 2002. p. 81-91.

JACKSON, John H. The jurisprudence of Gatt and the WTO: insights on treaty law and economic relations. Cambridge; Nova York; Melbourne: Cambridge University Press, 2000.

KOGAN, Lawrence A. A framework for evaluating whether a non-tariff measure has matured into an actionable non-tariff barrier to trade. American University International Law Review, v. 28, n. 2, p. 489-668, 2013.

LOWE, Vaughan. Sustainable development and unsustainable arguments. In: BOYLE, Ala; FREESTONE, David (Ed.). International law and sustainable development: past achievements and future challenges. Nova York: Oxford University Press, 2001.

OLIVEIRA, Bernardo Carlos S. C. M. de; SANTOS, Luis Miguel L. dos. Compras públicas como política para o desenvolvimento sustentável. Rev. Adm. Pública, v. 49, n. 1, p. 189-206, jan./fev. 2015.

PETERSMANN, Ernst-Ulrich (Ed.). Reforming the world trading system: legitimacy, efficiency and democratic governance. Oxford: Oxford University Press, 2005. 
PHILIP, André. La Conférence de Genève, amorce d'un mouvement mondial irréversible. Développement et Civilisations, n. 19, p. 23-35, set. 1964.

RAMANZINI JUNIOR, Haroldo; VIANA, Manuela T. Países em desenvolvimento em uma ordem internacional em transformação: coalizões e soluções de disputas na OMC. Revista Brasileira de Política Internacional, Brasília, v. 55, n. 2, p. 48-69, dez. 2012. Disponível em: <www.scielo.br/scielo.php?script $=$ sci_arttext\&pid=S0034-73292012000200004\&lng=pt\&nrm=iso > . Acesso em: 25 fev. 2015 .

RELATÓRIO BRUNDTLAND. Report of the World Commission on Environment and Development: our common future, 1987. Disponível em: <www.un-documents.net/wced-ocf.htm>. Acesso em: 25 fev. 2015.

SCHRIJVER, Nico; WEISS, Friedl. International law and sustainable development: principles and practice. Leiden; Boston: Martinus Nijhoff Publishers, 2004.

SHAFFER, Gregory. The WTO tuna-dolphin II case: United States - measures concerning the importation, marketing and sale of tuna and tuna products. Minnesota Legal Studies Research Paper, n. 12-62, 2012.

THE LIMITS OF GROWTH. A report to the Club of Rome, 1972. Disponível em: <www.clubofrome. org/docs/limits.rtf>. Acesso em: 25 fev. 2015.

THORSTENSEN, Vera. OMC. Organização Mundial do Comércio. As regras do comércio internacional e a rodada de negociações multilaterais. 2. ed. São Paulo: Aduaneiras, 2003.

UNITED NATIONS. Indicators of sustainable development: guidelines and methodologies, 2001. Disponível em: < https://sustainabledevelopment.un.org/publications/indisd-mg2001.pdf> . Acesso em: 25 fev. 2015.

VAN BELLEN, Hans Michael. As dimensões do desenvolvimento: um estudo exploratório sob as perspectivas das ferramentas de avaliação. Revista Ciência da Administração, v. 12, n. 27, p. 143-168, 2010.

VEIGA, José Eli. A emergência socioambiental. São Paulo: Senac, 2007.

VIRALLY, Michel. Vers un droit international du développement. Annuaire Français de Droit International, v. 11, p. 3-12, 1965.

VIZEU, Fabio; MENEGHETTI, Francis K.; SEIFERT, Rene Eugenio. Por uma crítica ao conceito de desenvolvimento sustentável. Cad. EBAPE.BR, v. 10, n. 3, p. 569-583, 2012.

WTO.Dispute settlement. Disponível em: <www.wto.org/english/tratop_e/dispu_e/dispu_status_e. htm >. Acesso em: 25 fev. 2015.

YIN, Robert K. Case study research: design and methods. Londres: Sage, 1989.

Ligia Maura Costa é livre-docente em direito internacional e professora titular do Departamento de Fundamentos Sociais e Jurídicos (FSJ) da Fundação Getulio Vargas, Escola de Administração de Empresas de São Paulo (FGV-Eaesp). E-mail: ligia.costa@fgv.br. 